Diabetes and Metabolic Syndrome: Clinical Research and ReviewsVolume 12, Issue 4, July 2018, Pages 531-535

\title{
Association between free thyroid hormones values and the lipid profile in middle-aged women with chronic symptoms(Article)
}

- Guarnizo-Poma, M.aEmail Author,

- Paico-Palacios, S. ${ }^{a}$ Email Author,

- Pantoja-Torres, B. ${ }^{a}$ Email Author,

- Lazaro-Alcantara, H. ${ }^{2}$ Email Author,

- Urrunaga-Pastor, D.aEmail Author,

- Benites-Zapata, V.A. ${ }^{\circ}$ Email Author,

- Insulin Resistance and Metabolic Syndrome Research Group

- View Correspondence (jump link)alnstituto Médico de la Mujer/Instituto Médico Metabólico, Lima, Peru

- $\quad$ 'Facultad de Ciencias de la Salud, Universidad Peruana de Ciencias Aplicadas, Lima, Peru

\section{Abstract_View references (45)}

Aims: To determine the association between the thyroid hormones(FT3, FT4 and TSH) and the lipid profile markers(HDL-C, LDL-C and triglycerides) values in middle-aged women with no metabolic disorders and recurrent chronic symptomatology. Materials and Methods: We carried out an analytical crosssectional study in euthyroid women with recurrent chronic symptoms of at least six months with no apparent diagnosis who attended the endocrinological gynaecology outpatient service of a private clinic in Lima-Peru during 20122014. Participants who met the eligibility criteria were evaluated according to their thyroid hormones(FT3, FT4 and TSH) and lipid profile markers(HDL-c, LDL-C and triglycerides) values. We elaborated univariate/multivariate linear regression models to evaluate the association between the thyroid markers and the lipid profile levels. The reported association measure was the beta coefficient $(\beta)$ with its respective $p$-value. Results: We analyzed 211 participants, the average age was $44.9 \pm 14.0$ (SD) years, the FT3 and FT4 mean levels were $3.2 \pm 0.4 \mathrm{pg} / \mathrm{mL}$ and $1.2 \pm 0.2 \mathrm{ng} / \mathrm{dL}$ respectively, while the TSH median was 2.8(IQR:1.9-4.0) $\mu \mathrm{U} / \mathrm{mL}$. The mean or median levels of LDL-c, HDL-C and triglycerides were of $137.5 \pm 37.9 \mathrm{mg} / \mathrm{dL}, 54.0 \pm 15.0 \mathrm{mg} / \mathrm{dL}$ and 118.5(IQR:79.5-169.5) $\mathrm{mg} / \mathrm{dL}$ respectively. In the multivariate linear regression model between the FT3 and LDL-c levels, we found that for each increase in a FT3 unit, the LDL-c values decreased on average $30.85 \mathrm{mg} / \mathrm{dL}(\mathrm{p}<0.01)$. We found no statistically significant associations in the other multivariate models of linear regression, among the other thyroid hormones and lipid markers. Conclusion: We found an inverse association between the FT3 and LDL-C values in women with chronic gynaecological symptoms. (C) 2018 Diabetes India 
Topic: Hypothyroidism | Thyrotropin | subclinical hyperthyroidism Prominence percentile: 95.827

Reaxys Database Information

View Compounds

Author keywords

Cholesterol, LDLDyslipidemiasThyroidTriiodothyronineWomen

Indexed keywords

EMTREE drug terms: high density lipoprotein cholesterolliothyroninelipidlow density lipoprotein c hormonethyrotropinthyroxinetriacylglycerol

EMTREE medical terms: adultArticlebody weight gainchronic diseasecross-sectional studyeuthyroidismfatiguefemaleheadachehumanmajor clinical studypriority jc diseasesymptomatologyvagina discharge

Chemicals and CAS Registry Numbers:

liothyronine, 6138-47-2, 6893-02-3; lipid, 66455-18-3; thyrotropin, 9002-71-5; thyroxine, $7488-70-2$

- ISSN: 18714021

- Source Type: Journal

- Original language: English

- DOI: $10.1016 / j . d s x .2018 .03 .023$

- Document Type: Article

- Publisher: Elsevier Ltd 